\title{
Neodločljivost v poeziji Tomaža Šalamuna
}

\section{Alen Širca}

Filozofska fakulteta Univerze v Ljubljani, Oddelek za primerjalno književnost in literarno teorijo, Aškerčeva 2, 1000 Ljubljana, Slovenija https://orcid.org/0000-0001-6292-344X alen.albin.sirca@ff.uni-lj.si

Razprava se ukvarja s poezijo Tomaža Šalamuna, in sicer skuša ovrednotiti njegov izjemno obsežen pesniški korpus v celoti. Najprej ponuja kratek (nepopoln) pregled pomembnejših kritiških in literarnozgodovinskih ocen Šalamunove poezije, potem pa analizira njegovo a finiteto do religioznega diskurza, ki ga ustvarjalno vpleta v svoje pogosto disjunktivne pesniške kompozicije. Vprašanje, ki se ob tem postavlja, je, ali gre tu v temelju za izrekanje neke religiozne izkušnje oziroma hrepenenja po njej in s tem za poezijo, ki izreka neki »metafizični smisel, ali pa gre samo za simulacijo religioznega jezika in tako za "poezijo površine"v neoavantgardnem ključu? Ob pomoči Derridajevega koncepta "neodločljivosti « članek pokaže, da je Šalamunova poezija strukturirana tako, da se je nemogoče odločiti tako za eno kot za drugo opcijo. Na koncu članek opozarja na to, da je Šalamun pomembno vplival tudi na srbsko pesniško od sedemdesetih let 20. stoletja naprej. Kratka analiza pesmi "Šalamun "Nenada Jovanovića ponuja spodbudo za ta slabo raziskani literarni vpliv slovenske literaturo na srbsko.

Ključne besede: slovenska poezija / Šalamun, Tomaž / neoavantgarda / literarni vplivi / newyorška šola / religiozni jezik / neodločljivost / Derrida, Jacques

Tomaž Šalamun je eden izmed največjih slovenskih pesnikov, ki ima hkrati tudi najobsežnejši pesniški opus, saj je med letom 1966, ko je izšel njegov prelomni prvenec Poker, in vse do svoje smrti leta 2014 izdal skoraj 50 pesniških zbirk. ${ }^{1}$ Poleg tega pa lahko z gotovostjo trdimo, da je tudi eden izmed najvplivnejših slovenskih pesnikov 20. stoletja. Njegove posamezne zbirke in antologije so bile doslej prevedene v več kot 20 jezikov, še posebno pa je znan v Ameriki, kjer je vplival na številne pesnike,

${ }^{1}$ Razprava je nastala v okviru raziskovalnega projekta "Slovenska literatura in družbene spremembe: nacionalna država, demokratizacija in tranzicijska navzkrižja“ (J6-8259), ki ga je sofinancirala Javna agencija za raziskovalno dejavnost Republike Slovenije iz državnega proračuna. 
predvsem na tiste, ki so bili $\mathrm{v}$ sedemdesetih letih in še pozneje znani pod imenom Language poets (ali $L=A=N=G=U=A=G=E$ poets) in so v ameriško poezijo vnašali številne avantgardne eksperimentalne postopke.

Šalamunova poezija je doslej naletela na več razlag. Slovenska literarna zgodovina jo na splošno povezuje s slovensko pesniško neoavantgardo, ki je nastopila v drugi polovici šestdesetih let prejšnjega stoletja. Šalamun je na začetku svoje pesniške kariere sodeloval s slovensko neoavantgardno skupino OHO. Tako Tomaž Brejc njegovo poezijo razume kot sestavni del OHO-jevskega reizma, pri katerem »besede berejo same sebe«:

$[\ldots]$ in to je šalamunovski reizem, ne toliko filozofska disciplina ali poljubna igra $s$ stvarmi kot predvsem dejavna strategija besednega razporejanja, kajti iz brbotanja besedne množice se z elastično, naglo in spretno gesto izpostavljajo posamične besede, ki se nato zrcalno berejo v sebi, vzpostavljajo tekst, a nikoli ne postanejo plen romantičnega, simbolističnega metaforiziranja: beseda se bere, postavi se druga ob drugo, zaplete se $\mathrm{v}$ metonimični niz in ostra presoja njihovega učinkovanja zamejuje puhlo in obupajoče "samoiskanje», „izražanje« pesniškega subjekta, tisto velikokrat brezsmiselno obotavljanje z velikimi kategorijami življenja in smrti, ki se največkrat pretopijo v pomilovanje tistih, ki jih uporabljajo, in le silno redko v poezijo. $(942-943)^{2}$

Šalamunova poezija naj bi bila upor proti romantičnemu pesniškemu izročilu, zato je njen jezik demetaforiziran, pa tudi deritmiziran in demelodiziran. Tu torej ne gre niti za romantični izraz afektivne notranjosti niti za depersonalizirano evokacijo état d'âme (»stanja duše»), ampak za vsaj delno kontrolirano, kalkulirajočo jezikovno igro.

Skoraj docela nasprotno presoja Šalamunovo poezijo Aleš Debeljak. Ta v enem izmed svojih kritiških zapisov pravi, da se za neskončnim metonimičnim tokom besed v Šalamunovih pesmih vendarle skriva neki horizont smisla, in sicer čudenje temu, zakaj sploh je svet. Tako se po njegovem v Šalamunovi poeziji »hermetizem modernistične tradicije srečuje z dosežki ulične kulture in empiričnih zemeljskih podatkov zato, da ne bi ukinila strašnega zakaj sveta, marveč da bi ga vrnila kot vprašanje - svet kot vprašanje, potemtakem" (Debeljak 87).

Nasprotno Boris Paternu nima enotnega odgovora na Šalamunova besedila, zato je negotov glede tega, kako bi literarnozgodovinsko opredelil njegovo poezijo. Ugotavlja namreč, da se razrašča v različne slogovno-formalne smeri: »Tako je Šalamunovo izražanje včasih do kraja veristično, drugič simbolistično, pogosto nadrealistično, nemalokrat

\footnotetext{
${ }^{2}$ Prvotno objavljeno kot predgovor k drugi izdaji zbirke Poker (1989).
} 
hermetično in mestoma že čista glasovna igra besed, izpraznjenih razvidnega pomena" (Paternu 175).

V podobni zagati je tudi Denis Poniž, ki pa vendarle v Šalamunovem opusu opaža nekakšen razvoj. Po prvi, razbijaški fazi v poznih šestdesetih naj bi Šalamun v začetku sedemdesetih prešel v mameriško fazo«, saj naj bi ob soočanju s številnimi ameriškimi pesniki raziskoval prostor poezije $\mathrm{v}$ najrazličnejših smereh. Potem naj bi sledila tretja faza, ki naj bi se začela z zbirko Metoda angela (1978) in naj bi obsegala še sedem naslednjih zbirk, pri čemer pa naj bi se njegova lirika zdaj umirjala in se čedalje bolj obračala $\mathrm{v}$ intimo, $\mathrm{k}$ iskanju smisla, ki »naj presvetli pesniško početje in zaznamuje pesniški jezik" (Poniž 4). Nazadnje naj bi Šalamun z zbirko Soy realidad (1985) prešel še v četrto fazo, pri kateri pa naj bi prevladovali postmoderni elementi tako v vsebinskem kot oblikovnem pogledu, tako da naj bi se "skoraj baročna razkošna metaforika svobodnih asociacij« dokončno umirila, Šalamun pa naj bi se zatekel $\mathrm{k}$ »t. i. remakom lastnih pesniških postopkov in besedil iz zgodnejših obdobij« (prav tam). Tu gre seveda za pregled opusa do sredine devetdesetih.

Tudi Janko Kos se je večkrat kritiško loteval Šalamunove poezije. Ta v zvezi z njegovo zgodnjo poezijo (ob zbirki Namen palerine, ki je izšla za Pokrom) ugotavlja, da se Šalamunov pesniški govor po vzoru nadrealistov odeva v nekak odrasel »infantilizem«, ki s svojimi jezikovnimi igrami izreka nihilistično stanje sodobnega sveta. Pri tem pa uporablja tudi "popartistične« ready-made, ki jih najdeva v raznih diskurzih povsod okoli sebe (Kos, »Tomaž Šalamun« 337-340). Veliko pozneje pa Kos v svoji Primerjalni zgodovini slovenske literature (2001), potem ko je bil večidel Šalamunovega opusa že napisan, Šalamunovemu pesništvu z duhovnozgodovinske perspektive nameni te besede: »Potem ko je Šalamun že sredi šestdesetih let iz svoje poezije izločil vse postsimbolistične in eksistencialistične prvine, je s svojim zgledom večji del mlajših pesnikov usmeril v ultramodernizem. Temu je ostal zvest tudi sam s številnimi zbirkami, ki so izhajale od začetka sedemdesetih let do poznih devetdesetih" (386). Toda Kos ugotavlja, da Šalamunov opus ni monoliten, saj je v njem vendarle zaznati neki premik, razvoj:

Kljub temu je v zaporedju tega plodnega, na videz zmeraj enakega pesništva opaziti premik, ki se za prehod v pesniško postmoderno zdi značilen. Medtem ko je v prvih zbirkah svoje pesništvo oblikoval kot sledenje popolnoma svobodnemu, vsega eksistencialnega, realnega in metafizično temeljnega prostega toka zavesti, ki po nadrealističnem načelu avtomatične pisave sprošča poezijo $\mathrm{v}$ neizčrpen, neusmerjen in samozadosten krogotok asociacij, preskokov in nelogičnih pojmovnih zvez, se je zdaj ta nadrealistični način močneje oprl na kult 
pesniškega Jaza, ki je v daljnem rodu $\mathrm{z}$ Whitmanovo patetično samoprezentacijo, kar pomeni, da se je Šalamunov prvotni anarhonihilistični modernizem vrnil k izročilom nove romantike ... (386-387)

Po Kosovi sodbi je Šalamunov razvoj očitno v resnici regresija, korak nazaj, v predmodernistično poezijo (neo)romantičnega kova, ki je zaznamovana s trdno subjektiviteto. Kakor koli že, večina kritikov in literarnih zgodovinarjev bi verjetno pritrdila mnenju, da Šalamunova poezija, $v$ celoti gledano, ni tako enolična, kot se morda zdi na prvi pogled. Že od začetka lahko v njej pravzaprav razbiramo vsaj dva tipa pesniškega govora. Prvi tip je najočitnejši, to je reistično-nadrealistična, fragmentarizirana poetika, pri kateri so različne, celo disjunktivne izjave postavljene druga za drugo. Pesniški govor pa teži k dehierarhizaciji vseh diskurzov in se ponekod $\mathrm{v}$ skoraj dadaistični aleatoriki upira poenotenju v celovito, organsko pesem, značilno za "zmerni« tip modernizma, ki je pri nas prevladoval v povojni poeziji 20. stoletja.

To lastnost so opazili tudi tuji poznavalci poezije. Ugledni ameriški pesnik Robert Hass o Šalamunu v svojem uvodu v izboru Šalamunove poezije, ki ga je naredil Charles Simic, ${ }^{3}$ na primer pravi, da je Šalamunov slog $\mathrm{v}$ jedru nadrealističen in je zato dedič disruptivne in hkrati vizionarske plati evropske eksperimentalne umetnosti, ki sega nazaj k Rimbaudu in Lautréamontu in se prek ruskih futuristov, predvsem Hlebnikova, izteza $\mathrm{k}$ Apollinairu in francoskemu nadrealizmu z Bretonom na čelu.

To literarno dediščino preiskuje tudi Marjorie Perloff, ki je ena izmed vodilnih ameriških preučevalcev sodobne ameriške poezije. $\mathrm{O}$ njej govori kot o "drugem izročilu" (the Other Tradition), ki se, kolikor sega nazaj $\mathrm{k}$ Rimbaudu, imenuje tudi "francoska povezava" (the French connection) (Perloff, Poetics 33). Ta pesniški tok naj bi bil znotraj modernizma samega $v$ nasprotju z literarnim idiomom t. i. "visokega modernizma" (high modernism), ki v temelju vendarle nadaljuje simbolistični način pesnjenja, saj z uporabo simbolov in z enigmatičnim, hermetičnim govorom na splošno še vedno želi evocirati bistvo sveta, čisto notranjost, transcendenco itn. (recimo T. S. Eliot, Yeats, W. Stevens). Nasprotno pa je za »drugo izročilo« po njenem značilna eksperimentalna literatura, nekakšen »literalizem«, poetika igre površine, procesualnosti, ki goji disjunktivne metonimične relacije (10) ter asociativno ritmiko podob in besed, ki se nikdar ne poglobijo v metafore. Temu izročilu naj bi bilo v Ameriki mogoče slediti od Gertrude

${ }^{3}$ The Selected Poems of Tomaž Šalamun, New York: The Ecco Press, 1988. Ta knjiga mi ni bila dosegljiva, zato povzemam po Hirsch xii. 
Stein, Ezra Pounda, Williama Carlosa Williamsa pa vse do Johna Caga in Johna Ashberryja, ki naj bi v šestdesetih letih 20. stoletja prispevala $\mathrm{k}$ temu, da se je v ameriški poeziji počasi nekako pometlo $s$ "hegemonijo simbolizma« (35).

Šalamuna bi po tej analizi lahko gladko uvrstili med pripadnike tega »drugega izročila«. Vsekakor bi bilo koristno celovito preiskati kritiško recepcijo Šalamuna v Ameriki, ampak za to tu žal ni prostora. Ameriški kritiki večinoma poudarjajo avtentičnost Šalamunove poezije, ki pa je težko opisljiva oziroma natančneje konceptualno zagrabljiva. Tako recimo Matthew Rohrer poudarja relacijskost Šalamunove poezije, ki naj bi v svoji domišljijski alogiki kazala na neko "višjo geometrijo«: "[Śalamunova] skrb ni kratko malo usmerjena na jezikovne prvine ali podobe ali različne glasove, ampak je usmerjena nanje v celoti, da bi izrazila nekaj večjega od tega« (58). Čeprav gre za poezijo, ki je "fantastična«, naj bi bila vendarle emotivna in mentalna tonaliteta teh pesmi izjemno konsistentna in naj bi kljub liričnosti celo omogočala »simbolično in skoraj geometrično razumevanje dogodkov« (Rohrer 59).

Zanimivo je tudi mnenje Kevina Harta, ki trdi, da je za Šalamuna značilna nekakšna proti-izkušnja, ki skuša v bralcu inducirati "zmešnjavo", prevrat njegovega védenja, čutenja, pričakovanja. Zato po njegovem Salamunova pesem "ni toliko odraz izkušnje kot poskus, kako nas v aktu branja izpostaviti tistemu, kar izkušnjo bega» (Hart 962). Poleg tega pa v nekaterih pesmi pri Šalamunu zaznava vpliv Franka O'Hare, med drugim tudi v njegovi znani pesmi »Balada za Metko Kraševec« (Hart 960).

\section{Vpliv »newyorške šole»}

Ta ugotovitev je pomembna, saj nas pelje k drugemu tipu Šalamunove poezije. Ta vtis potrjuje tudi Edward Hirsch, ki v svojem predgovoru (»Foreword«) k izboru Šalamunove poezije ugotavlja: »Slišim pa v teh pesmih tudi nekaj od improvizirani slasti in vsakdanjosti pesnikov iz New Yorka [I also hear something of the improvisatory delight and dailiness of the New York Poets in these lyrics] « (xii). Vse to govori v prid dejstvu, da je bila Šalamunova poezija v marsičem spodbujena od ameriške poezije petdesetih in šestdesetih let 20 . stoletja, ki jo zelo posplošeno lahko imenujemo poezija beat generacije, čeprav je morda poglaviten Šalamunov vzor t. i. newyorška šola (New York School) s Frankom O'Haro na čelu. Ta skupaj z Johnom Asberyjem, Kennethom Kochom in Jamesom Schuylerjem velja za začetnika tega vplivnega pesniškega 
gibanja. Za pesniški jezik te šole je še posebno značilno zadrževanje na površini izkušnje, ki je tipična za sodobnega urbanega človeka, pri čemer so od slogovnih postopkov najbolj v oči bijoča katalogiziranja takih in drugačnih personalia, ki je docela razumljivo samo ozki bohemski klienteli oziroma elitni literarni côterie. ${ }^{4}$

Slovenska javnost se je $s$ takšno novo poezijo seznanila že $\mathrm{v}$ zgodnjih šestdesetih, zlasti pa od leta 1963 naprej, ko sta nekatere bitniške pesmi prevajala Niko Grafenauer in Mart Ogen. ${ }^{5} \mathrm{~V}$ tem oziru je zelo pomembna predvsem zadnja številka Perspektiv (Leto IV, 1963-1964), v kateri je sodobni ameriški poeziji posvečeno kar nekaj prostora, med drugim tudi prevedeni odlomki Ginsbergovega Howla (Tuljenje I), in "pesem " Franka O'Hare. Prav tako tu naletimo na prevod različnih pesniških poetik ameriških pesnikov beat generacije, naslovljen " $\mathrm{O}$ sodobni ameriški poeziji«.

Z ozirom na to je pomenljivo dejstvo, da lahko pri Šalamunu še pred izidom Pokra (1966) naletimo na pesmi, ki so napisane po vzoru newyorške šole. Tak je na primer cikel »Ribe«, objavljen leta 1965 v študentski reviji Tribuna. Gre za pesmi: "Niniche«, "Kenguru«, »Pogreb« in "Smrt na č«. Od tega je v maniri newyorške šole najbolj očitna pesem »Pogreb« z začetnim verzom: »Ko je umiral Pavel, ostrižen na krtačo / baje sploh ni mogel nič ziniti ...«(7).

Ta vpliv v Šalamunovi poeziji potem najjasneje opazimo predvsem v zbirkah, ki so nastale $\mathrm{v}$ sedemdesetih letih in $\mathrm{v}$ prvi polovici osemdesetih let. Naj omenim samo nekaj takih pesmi: v zbirki Amerika (1972) je recimo taka pesem z začetnim verzom »Trenutno sem zaljubljen v Boba Perelmana« (glej Šalamun, Kdaj 172-173), potem »Prvič, ko sem prišel v New York City" iz zbirke Praznik (1976) (glej Šalamun, Kdaj 272276), potem pesem "Kdo je Imre" (Zvezde 1977), "Slavolok«, "Sveti trije kralji kanibali« (Maske 1980), pa tudi že omenjena pesem »Balada za Metko Krašovec« iz istoimenske zbirke (Šalamun, Balada 1981).

\footnotetext{
${ }^{4}$ Glej o tem Marjorie Perloff (1977) in Shaw (2006). Shaw poudarja (6 isl.), da gre pri côterie vedno za preplet socialnega in literarnega, ter meni, da bi bilo treba pri "pozitivnem» dojemanju literarne »koterije« biografske detajle brati kot nekakšno posebno vrsto branja, ki bi premoščalo vrzel med biografskimi partikularijami in retoriko ter posledično tudi estetiko (teorijo), ali kratko malo, med življenjem in tekstom (literaturo).

${ }^{5}$ Zanimivo je, da je Ogen kritično nastopil zoper Grafenauerjeve prevode, češ da se opazi, da Grafenauer niti jezika dovolj dobro ne pozna, predvsem pa ga je zbodla njegova negativna sodba o tej poeziji, ki jo je označil za dekadenčen pojav (Ogen 1183-1188).
} 
Vsakdanja izkušnja, ki pogosto učinkuje tako, kot da bi bila reproducirana iz lastnega dnevniškega zapisa, je pri Šalamunu ves čas navzoča $\mathrm{v}$ fragmentih kot eden izmed poglavitnih rezervoarjev za njegove asociativne pesniške kompozicije. Pa vendar se Šalamunov oseben, včasih že kar privaten "I do this, I do that" - kot je slovito označil poetiko Franka O'Hare njegov newyorški pesniški kolega Ted Berrigan (Shaw 42) - osamosvoji v samostojno, narativno oblikovano pesem. Takšni "oharizmi« so pri Šalamunu na primer katalogi dnevnih aktivnosti, navajanje različnih (mikro)lokacij, osebnih imen, ki so docela razumljivi samo njemu samemu ali njegovi osebni côterie, pa tudi tematizacija prijateljstva in ljubezni, tudi homoseksualne.

Čeprav ima newyorška šole na prvi pogled izrazite predmodernistične poteze, pa je vendarle res, da ima globoke vezi z evropsko avantgardo, ki ji je sicer zavezana tudi Šalamunova poezija. Treba je namreč poudariti, da gre pri poeziji Franka O'Hare v resnici za enega izmed načinov presajanja evropske avantgarde na tla povojne ameriške poezije. Zato Marjorie Perloff v zvezi z O'Haro po pravici opozarja na avantgardistično pesniško tradicijo, zlasti na Apollinaira in Majakovskega, ki ju je imel O'Hara za velika vzornika (Perloff, Frank O'Hara xiii).

\section{Šalamun o Šalamunu}

Ker je Šalamunova poezija tako raznovrstna, je mogoče na podlagi nekaterih pesmi, vrstic in stavkov v njej interpretativno sklepati o nekaterih potezah Šalamunove poetike, seveda ob predpostavki, da so to vendarle enote smisla, ki štrlijo iz pogosto nerazumljive jezikovne gmote. Razberemo lahko vsaj to, da gre Šalamunu za de(kon)strukcijo tradicionalnega pesniškega jezika, tudi tistega "zmerno" modernističnega, ki je imel na Slovenskem primat skoraj vso drugo polovico 20. stoletja. Jezik takšnega pesništva naj bi v izrekanju metafizičnih vprašanj zaobšel človeško "fiziko« in se tako povampiril, kot je rečeno v pesmi z naslovom »Himna svetovne odgovornosti «:

Prinašamo ljubezen in svobodo brez sovraštva.

In ti, povampirjeni jezik,

ki si izdal telo od strasti, da bi obljudil

neznan dežele,

napak! (Šalamun, Kdaj 294) 
Še posebej pa je Šalamun napadel navezavo metafizičnosti z nacionalno vzvišenostjo tradicionalne slovenske poezije, se pravi, če uporabim oguljeno sintagmo Dušana Pirjevca, "prešernovsko strukturo" večjega dela slovenske poezije. $\mathrm{V}$ pesmi iz zbirke Metoda angela $\mathrm{z}$ začetnim verzom "Biba leze, biba gre« beremo:

Nate se torej naslanjam,

nacionalni vampir.

Počakaj, da se primerno razžarim.

Enkrat te bom zrušil. (Šalamun, Kdaj 344)

Vendar ta, ki ruši, ni več »močni« subjekt prevrata, revolucije, ampak nekdo neprimerljivo bolj porozen. Bistvu Šalamunove pesniške prakse oziroma metode, ki ji sam pravi "metoda angela«, je disperzija (govorečega, pesniškega) subjekta. Šalamun oziroma njegov pesniški subjekt ni človeški, ampak »angelski«, vendar ne v smislu kakega mitološkega bitja, ampak kot nenehno razblinjanje in pršenje:

\section{Metoda angela}

Nikoli nisem bil človek, vedno angel.

Ko pride do svoje popolne oblike se

razprši. (Šalamun, Kdaj 336, glej tudi Šalamun, Metoda 103)

Zato je Šalamunov pesniški subjekt morda samo razlika med označevalci, ki lebdi v "belem prostoru" med besedami jezika, ki se briše: "Jaz sem bel, brisan prostor. / Kar se zgodi, se zgodi« (Šalamun, Kdaj 333). Je hkrati suženj in gospodar besede, jezika: »Beseda je edini temelj sveta. / Jaz sem njen služabnik in gospodar" (247). Kot tak je jaz nespoznavna instanca, večna enigma: "Ne poznam se. / Nikoli se ne bom mogel spoznati« (Šalamun, Metoda 92).

Za Šalamuna je bilo značilno, da se ni rad izrekal o svoji ustvarjalnosti. Ni rad »teoretiziral«. Rad bi se navezal še na eno izmed recentnejših pričevanj, in sicer na pogovor z Gorazdom Kocijančičem z naslovom "Kaj je pesniška knjiga«. Tu Šalamun govori o čudnosti, v katero ga kliče sam jezik (Kocijančič, 49). Nekoliko natančneje oriše svoj ustvarjalni proces, ki potrjuje prejšnje navedke iz Šalamunovih pesmi:

In tudi jaz sam imam pri teh pesmih, ko jih berem, občutek, da se bom takoj razburil in se takoj zaprl, ker to nima nobenega smisla. Ker pa vem, da je to nastalo, ne ker bi jaz tako hotel, ampak ker je jezik tako vstopil na bel papir oziroma vame in se tako dogaja, počakam in gledam. Zelo čudno. Se napiše, 
pride stavek, potem ni pa nič. Pa dva dni nič. Potem pa recimo pet stavkov in ti stavki so v sorodu, se vežejo, ker so nastali v istem, ne vem, kaj je to, v isti magmi, v isti mani, v istem zvenu, takrat ko te pač jezik pokliče. (38)

Šalamun torej pričuje o nekakšni epifaniji jezika, pri čemer je avtor (Šalamun) pasiven in skoraj kot nekakšen medij oziroma objekt zapisuje to, kar vanj polaga »Subjekt«, Jezik sam, ki ga ima Šalamun očitno za nekakšno (kvazi)transcendenco.

\section{Šalamun in religija}

Šalamun ima zelo velik arzenal motivov, tem, diskurzov, ki jih vpleta $\mathrm{v}$ svoje pesmi. Vendar pa pregled njegovega celotnega opusa daje vtis, da ima še posebno veliko afiniteto do religioznega diskurza. To doslej na Slovenskem skoraj ni bilo tematizirano. ${ }^{6} \mathrm{~V}$ Šalamunovih tekstih na obilo religioznih drobcev, izrazov in motivov naletimo že v sedemdesetih letih, pri čemer so ti pogosto nabiti z nekakšno kozmično mistiko, "hipijevskim" panteizmom, ki najbrž odsevajo njegovo "ameriško" izkušnjo. Taki so na primer verzi iz pesmi "Sam» (Šalamun, Arena, 1973): »Bog sem. / Bog sem in plešem. [...] Sam sem center svetlobe sveta, gospodovo jagnje» (Šalamun, Kdaj 227).

Vsekakor pa ti religiozni elementi postanejo v osemdesetih letih čedalje pogostejši in zato toliko bolj opaznejši. V zbirki Balada za Metko Krašovec (1981) naletimo na precej takšnih odlomkov. Na primer zelo izrazito v pesmi "San Juan de la Cruz in John Dilg«:

Moj bog je kruta rumena žuželka,

naseljuje se, kjer se sam hoče.

Klovn! Nobenemu tvojemu triku več ne

sledim! Moj bog je tisoč bliskov v enem

samem koščku sladkorja ... (Šalamun, Kdaj 432)

Ali pa začetek pesmi »Žuželke ptiči«:

Čutim

roko boga na svojem tilniku.

Kdo si mi upa zmečkati glavo! (433)

${ }^{6} \mathrm{Na}$ to sestavino Šalamunovega pesništva opozarja Gorazd Kocijančič, ki v svojem intervjuju s pesnikom pravi: »Ti vedno v poeziji govoriš o teh religioznih pojmih vera, nagovor, poslušanje ... (Kocijančič 57). 
Ali pa pesem, ki je naslovljena kratko malo »Bog«:

\author{
Jaz zahtevam \\ brezpogojno \\ ljubezen \\ in \\ popolno \\ svobodo. \\ Zato sem strašen. (450)
}

Takšnih religioznih in celo teoloških drobcev iz različnih Šalamunovih zbirk v osemdesetih in devetdesetih je polno. Na primer: „Bog je Prazno « (433); "Jaz sem religiozen" (466); "Jaz sem Bog in človek obenem« (468); "Jaz sem Bog, ker ljubim" (469); "Razmišljam o Bogu, namesto da bi razmišljal o / snegu. Ni res. / Bog razmišlja o meni in me jé« (482); "Jaz živim tam, kjer me hoče Bog" (485); "Ne pustijo mi, da bi se dotaknil Kristusa" (512); „O Bog, zakaj me enostavno ne prekineš v slasti!« (566); "Hropsti od vsemogočne slasti Boga" (577); "[...] sila Boga te pa meče kot žlikrof v tla" (600); "Samo za lučaj sem od Boga« (607); "Jezik je rešitelj ljubezni, / rož, človeštva in instrument Boga« (625); "Gospod me / bo oblil (631); „V Bogu je spet brizg in sok« (686); "Apofatičnost daje tisti sladki / okus samo mladim« (707-708). In še bi lahko naštevali.

$\mathrm{V}$ poznih osemdesetih se zanimivo tem dokaj generičnim religioznim propozicijam pridružijo tudi elementi, ki merijo na področje judovske mistike, predvsem kabale. Na primer pesem, ki se začne z vrstico "Gerschom Scholem mi pa pravi drugače» (546) ali pa pesem "Abraham Abulafia «" itn.

Po letu 2000 je zanimivo tega manj, saj spet prevladuje nadrealistični collage oziroma spontane asociacije kot nekakšna simulacija avtomatičnega pisanja, vse to pa je dobro začinjeno z navedki konkretnih imen, krajev, dogodkov itn. v slogu newyorške šole. Vendar tudi tu ponekod spet vznikajo posamični fragmenti, ki učinkujejo kot hipni prebliski lucidnosti, kot vdori simboličnega, smisla, za katere se zdi, da postavljajo pod vprašaj površinsko igro jezika, pri kateri so vsakršni pomeni samo stranski učinki, semantična "pirotehnika". Na primer: "Moja poezija že zdavnaj ni več / verodostojna. // Od samega žarenja gnije» (783). Ali pa: »Mogoče bi nehal s to pirotehniko / in se spomnil, kaj je bilo zares« (888).

In zdaj končno, poglavitno vprašanje: ali je Šalamun pesnik površine ali pesnik globine? Ali pa se celo ni mogoče odločiti za nobeno od teh

\footnotetext{
${ }^{7}$ Angleški prevod te pesmi je objavljen v Šalamun, „Abraham Abulafia«160.
} 
opcij, in sicer v smislu, da njegova poezija pravzaprav razgrajuje samo razliko med obema načinoma pesnjenja. Da bi odgovorili na to vprašanje, skočimo za hip k Derridaju in njegovemu konceptu neodločljivosti. ${ }^{8}$

\section{Kaj je neodločljivost?}

Čeprav je koncept neodločljivosti, formalno gledano, stara filozofsko tema, ki je dobila svojo klasično obliko v paradoksu t. i. Buridanovega osla, pa jo je v 20. stoletju v filozofskem smislu najplodneje razvijal Jacques Derrida. Gre za, najpreprosteje rečeno, to, da je neka beseda, izjava ali celo besedilo neodločljivo, če sta nasprotujoči si branji enako možni in se ni mogoče odločiti za nobeno od njih.

Derrida v svojem klasičnem delu La dissémination (1972) na ozadju Mallarméjevega teksta Mimique zapiše, da neodločljivost ni nikakršna ambivalenca, torej semantični fenomen, ampak je - v navezavi na Gödlove »neodločljive propozicije« (iz njegovega spisa »Über formal unentschiedbare Satze der Principia Mathematica und verwandter Systeme«) - emfatično formalno-strukturnega značaja:

"Neodločljivosti« [»indécidabilité»] tu ne povzroča neka enigmatična dvoumnost, neka neizčrpna ambivalenca besede $\mathrm{v}$ »naravnem « jeziku in še manj kak Gegensinn der Urworte (Abel). Tu ne gre za to, da bi glede na hymen ponovili to, kar je počel Hegel z nemškimi besedami, kot so Aufhebung, Urteil, Meinen, Beispiel itn. ter se pri tem čudil naključju, ki postavlja naraven jezik v element spekulativne dialektike. To, kar tu šteje, ni leksikalno bogastvo, semantična neskončnost besede ali pojma, njegova globina ali širina, sedimentacija, ki je proizvedla $\mathrm{v}$ njem dve protislovni plasti pomenjanja/označevanja [significations] (kontinuitete in diskontinuitete, znotraj in zunaj, identiteta in diferenca itn.). To, kar tu šteje, je formalna ali sintaktična praksa, ki ga sestavlja in razstavlja. (249)

Za Derridaja je Mallarméjeva pesniška beseda hymen (himen, deviška kožica), ki jo ima za najbolj simptomatično besedo Mallarméjeve Mimique, nereferencialna, se pravi, da nima nobene reference, ampak je inscenacija tega, za kar pri dekonstrukciji v jedru gre; torej, ki podobno kot drugi analogni Derridajevi "sinkategoremi«, kot so pharmakon, supplément, differance itn., zgolj kaže na tisto "vmes" (entre, inter), ki

${ }^{8}$ Čeprav je res, da tudi Perloffova uporablja izraz »neodločljivost « pri analizi »drugega izročila", ga nikjer natančno ne pojasnjuje in ga celo zamenjuje z "nedoločnostjo" (indeterminacy), hkrati pa zavrača navezavo na Derridajevo dekonstrukcijo (Perloff, Poetics 17-18). 
je posledica "nereduktibilnega ekscesa sintaktičnega nad semantičnim» (prav tam). Ta vmesnost, zev, pa je v zadnji instanci kar nemetafizični pogoj možnosti vsakršne semioze, tudi literature kot take.

Kakor koli že, pojem nedoločljivosti je neločljivo povezan z dejanjem branja. Kaj je namreč tista instanca, ki se lahko ali se per definitionem ne more odločiti: to je $\mathrm{v}$ resnici nekdo, persona, bralec, ti in jaz. Zdi se, da se je Derrida pozneje zavedal te zagate, saj je v devetdesetih o neodločljivosti vedno govoril v okviru svoje etike, predvsem ob pojmu odločitve (décision), za katero je značilno, da je paradoksno možna prav na podlagi fundamentalne neodločljivosti.

Tu žal ni prostora, da bi lahko vstopili v to problematiko. Za nas, za analizo Šalamunovega pesništva, je pomembno predvsem dejstvo, da je tekst sam, še preden pride do kakršne koli semantike, strukturiran tako, da se ni mogoče odločiti ne za to ne za ono, saj gre za neskončno oscilacijo med nasprotnimi možnostmi. Zato bi vsaka odločitev (za to ali za ono) po Derridaju pomenila spregled te temeljne poteze literarnega besedila in se zapletla $\mathrm{v}$ iluzorično gospodovanje, obvladovanje besedila, v to in ono "interpretacijo«, fantazmatsko stabilizacijo pomenov, smisla.

Za demonstracijo tega, da lahko Derridajev koncept koristno uporabimo pri analizi Šalamunove poezije (seveda ob predpostavki, da nam ni treba sprejeti vseh radikalnih ontoloških predpostavk njegove teorije jezika oziroma kar filozofije nasploh), še posebno na tistih mestih, ko posega po religioznih prvinah, ki so navadno signal, da bomo imeli opravka s smislom, z "metafiziko", si oglejmo pesem "Molusk«. To je zadnja pesem Šalamunove masivne avtoantologije z naslovom Kdaj iz leta 2011. Pa tudi zadnja pesem iz istoimenske zbirke Molusk (2013), leto pred njegovo smrtjo. Zdi se, da imamo opraviti s pesmijo, v kateri odmeva vsa Salamunova poetika. Pesem gre takole:

Molusk sem.

Obvezan s kavlji.

Polikan z

motornimi

vozili, a ne? Lakoto

prosim,

da me zagleda,

lakoto prosim, da se obrne

proč. 


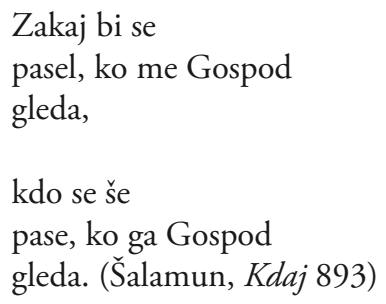

Molusk pomeni mehkužec. Če je rečeno, da je »obvezan s kavlji« in je nato celo "povožen" oziroma "polikan z motornimi vozili«, je to vendarle še smiseln pesniški stavek. Vendar pa ga takoj pomensko destabilizira vzklik »lakoto prosim«. Kaj sploh pomeni, da lakota zagleda jaz ali da se obrne proč od njega? In kaj potem temu dodata naslednji "kitici« oziroma stavek, ki zatava v docela religiozen register? Kdo je tu Gospod? Ali je to pogled bibličnega Boga Pastirja in gre tako za izrekanje neke religiozne izkušnje ali vsaj hrepenenja (»lakote«) po njej ali pa je to zgolj "mehka« jezikovna igra, ki samo simulira "trdo", "motorno" logiko metafizičnega govora in jo poljubno vstavlja oziroma zravenpostavlja drugim jezikovnim tvorbam?

Na ravni pesmi, pa tudi na ravni celotne zbirke in ne nazadnje celotnega Šalamunovega opusa se z vidika branja, bralske izkušnje, ni mogoče odločiti ne za to in ono. To je in očitno mora ostati neodločljivo.

\section{Neodločljiv odmev}

Posebno vprašanje, ki doslej še ni bilo dovolj raziskano, je vprašanje Šalamunovega enormnega vpliva. Konture njegovega vpliva v Ameriki do sredine devetdesetih so sicer znane (glej Maver), vendar še zdaleč ne zajamejo vsega. V prostoru nekdanje Jugoslavije je bila Šalamunova poezija zelo odmevna tudi v Srbiji, kjer je sprožila veliko spodbud za tamkajšnje neoavantgardno pesništvo, ki se je podobno kot v Sloveniji razmahnilo v sedemdesetih letih prejšnjega stoletja. Prav ta povezava bi si zaslužila natančno raziskavo. Vsekakor pa se zdi, da na enega izmed najbolj kongenialnih odmevov šalamunovske poetike "neodločljivosti« v zadnjem času naletimo v Srbiji pri Nenadu Jovanoviću. Ta je na pesniško prizorišče prišel $\mathrm{v}$ težavnih devetdesetih in se kot eden izmed najbolj talentiranih pesniških glasov svoje generacije postavil tako nasproti zgolj urbani poeziji, spodbujeni z ameriškimi zgledi, kot čedalje bolj dogmatskem tradicionalizmu v srbski poeziji, saj njegova poezija združuje elemente tako iz naravnega kot urbanega okolja. Gre 
namreč za "poetiko, ki je takoj postavila pod vprašaj opozicijo naravno/ kulturno« (Milošević 33).

Jovanovićevo pesem z nadvse pomenljivim naslovom "Šalamun" iz njegove zbirke Delfini (2014) lahko beremo kot svojevrsten hommage Šalamunu (»... ako si najveći pesnik Mitteleuropas«) ali pa kot demonstracijo šalamunovske jezikovne igre, presajeno v okvire svojega lastnega pesniškega mikrokozmosa. Vendar pesem kot celota nima nikakršnih odgovorov, morda niti nima smisla, zato $\mathrm{v}$ teh non sequitur stavkih zazija instanca neodločljivosti, ki razgrajuje vsakršno možno "pozitivno « interpretacijo in se navsezadnje, tako kot pri Šalamunu, ne moremo odločiti, ali gre za poetiko "globine» (»smisla«, "semantike«) ali pa za poezijo "površine» (golega označevalnega procesa).

\section{Šalamun}

Kada je sijalo sunce, pojavljivao si se kao dobar milicajac, a kada je padala kiša kao loš. Nije pomagalo što znam tvoje stihove o Satani, anfas osmehe na koricama i sve drugo što disidentstvo čini unosnim.

Dok je parking metar još otkucavao, kuću su ti obojili lažnom krvlju. Ona se pitala: „Gde sam?«, a ti si ćutao, da zadovoljiš fondacije. Kao što kaže De Sosir: ako si daleko od mora i oraha, ne znači da ne možeš mirisati na morski oraščić. To jest, ako si najveći pesnik Mitteleuropas, ne znači da ti ne pristaje izključivo deminutiv. Jer, ti si - da bi oživeo kita u jednoj svojoj pesmi ubio kitove u svim drugim svojim pesmama, pri čemu ti je sve otišlo u rok službe, u parking metar.

Drugim rečima: ono što sam ja plaćao tečnim tkivom, ti si platio tvrdom valutom. Pretnju zatvorom pretvorio u pretnju besmrtnošću, navodeći me da se pitam: šta si imao iz fizike? Je li protekcija počela još u školi?

Tamo gde leže odgovori, leži tvoj značaj. I to potrbuške. (22) 
Kakor koli že, gotovo lahko pritrdimo Šalamunovem verzu: »Ranjeni od Šalamuna imajo poseben / klub«(Šalamun, Molusk 41).

\section{LITERATURA}

Brejc, Tomaž. »Tomaž Šalamun in Julian Schnabel. Pesnik prihaja nasproti«. Kdaj: izbrane pesmi. Ur. Tomaž Šalamun in Aleš Šteger. Ljubljana: Študentska založba, 2011. 940-954.

Debeljak, Aleš. Melanholične figure: eseji o književnosti. Ljubljana: Univerzitetna konferenca, 1988.

Derrida, Jacques. La dissémination. Pariz: Seuil, 1972.

Hart, Kevin. "Iz revije Verse 18.2-3, 2001«. Kdaj: izbrane pesmi. Ur. Tomaž Šalamun in Aleš Šteger. Ljubljana: Študentska založba, 2011. 955-964.

Hirsch, Edward. »Foreword«. Tomaž Šalamun: Feast. Poems. Ur. Charles Simic. New York,San Diego in London: Harcourt, 2000. xi-xiii.

Jovanović, Nenad. Delfini. Kraljevo: Narodna biblioteka »Stefan Prvovenčani«, 2014.

Kocijančič, Gorazd. Kaj je --- knjiga?: pogovori s Tinetom Hribarjem, Tomažem Salamunom, Mladenom Dolarjem, Edvardom Kovačem, Jankom Kosom, Jankom Prunkom, Pavletom Rakom in Markom Uršičem. Ljubljana: Literarno-umetniško društvo Literatura, 2009.

Kos, Janko. »Tomaž Šalamun: Namen pelerine«. Sodobnost 17.3 (1969): 337-340.

Kos, Janko. Primerjalna zgodovine slovenske literature. Ljubljana: Mladinska knjiga, 2001.

Maver, Igor. "The Fortunes of a Slovene Poet in the U.S.: The Case of Tomaž Šalamun«. Slovene Studies 18.1 (1996): 19-38.

Milošević, Nenad. "Predgovor". Iz muzeja šumova: antologija novije srpske poezije (1988-2008). Ur. Nenad Milošević. Zagreb: V.B.Z., 2009. 13-37.

Ogen, Mart. "Beat generacija in njeno mesto v ameriški sedanjosti in literaturi«. Sodobnost 13.11 (1965): 1183-1188.

Paternu, Boris. Obdobja in slogi v slovenski književnosti. Študije. Ljubljana: Mladinska knjiga, 1989.

Perloff, Marjorie. Frank O'Hara: Poet among Painters. Austin: University of Texas Press, 1977.

Perloff, Marjorie. Poetics of Indeterminacy. Rimabaud to Cage. 3. izd. Evanston, Illinois: Northwestern University Press, 1999.

Poniž, Denis. "Šalamun, Tomaž.» Enciklopedija Slovenija. Zv. 13: Š-T. Ur. Dušan Voglar in dr. Ljubljana: Mladinska knjiga, 1999. 3-4.

Rohrer, Matthew. "Tomaž Šalamun«. Chicago Review 44.3/4 (1998): 58-60.

Shaw, Lytle. Frank O'Hara: The Poetics of Côterie. Iowa City: University of Iowa Press, 2006.

Šalamun, Tomaž. »Ribe«. Tribuna 15.16 (1965): 7.

Šalamun, Tomaž. Poker. Ljubljana: samozaložba, 1966.

Šalamun, Tomaž. Metoda angela. Ljubljana: Mladinska knjiga, 1978.

Šalamun, Tomaž. Balada za Metko Krašovec. Ljubljana: Državna založba Slovenije, 1981.

Šalamun, Tomaž. Soy realidad. Koper: Lipa, 1985.

Šalamun, Tomaž. "Abraham Abulafia». European Judaism: A Journal for the New Europe 41.2 (2008): 160. 
Šalamun, Tomaž. Kdaj: izbrane pesmi. Ljubljana: Študentska založba, 2011.

Šalamun, Tomaž. Molusk. Ljubljana: Cankarjeva založba, 2013.

\section{Undecidability in the Poetry of Tomaž Šalamun}

Keywords: Slovenian poetry / Šalamun, Tomaž / Neo avant-garde / literary influences / New York school / religious language / undecidability / Derrida, Jacques

The paper is dealing with the poetry of Tomaž Šalamun, and it attempts to evaluate his extremely extensive poetical corpus as a whole. Firstly, it offers a short (imperfect) overview of the some of the more important evaluations of Šalamun's poetry from the viewpoint of Slovenian literary criticism and literary history, and then goes on to analyze his affinity towards religious discourse, which is creatively integrated in his often disjunctive poetical compositions. The main question that arises is the following: are we dealing with some kind of religious experience or desire for it and thus with the poetry that in last analysis utters "metaphysical" sense, or are we dealing simply with the simulation of religious language and thus with the "poetry of surface" in the neo-avant-garde manner? With the help of the Derridean concept of undecidability, the paper demonstrates that Šalamun's poetry is structured in such a way that it is impossible to opt for one or the other option. At the end, the paper emphasizes that Šlamun's poetry has importantly exerted influence also on Serbian poetry from 1970s onwards. A short analysis of the poem "Šalamun" by Nenad Jovanović offers an incentive to research this not well studied literary influence of Slovenian literature in Serbia.

1.01 Izvirni znanstveni članek / Original scientific article

UDK 821.163.6.09-1Šalamun T.

DOI: https://doi.org/10.3986/pkn.v43.i2.05 